Copyright (c) 2008 IEEE.

Reprinted from the Power Electronics Specialists Conference (2008 :

Greece): pp.1542-1547

This material is posted here with permission of the IEEE. Such permission of the IEEE does not in any way imply IEEE endorsement of any of the University of Adelaide's products or services. Internal or personal use of this material is permitted. However, permission to reprint/republish this material for advertising or promotional purposes or for creating new collective works for resale or redistribution must be obtained from the IEEE by writing to pubs-permissions@ieee.org.

By choosing to view this document, you agree to all provisions of the copyright laws protecting it. 


\title{
Minimum Torque Ripple Current Control Strategy in a Dual Fault Tolerant PM AC Motor Drive
}

\author{
Jingwei Zhu*, Nesimi Ertugrul, and Wen Liang Soong \\ School of Electrical and Electronic Engineering \\ The University of Adelaide, Adelaide, Australia, SA 5005 \\ *Email: jingwei.zhu@adelaide.edu.au
}

\begin{abstract}
In this paper a dual fault tolerant motor drive utilizing brushless permanent magnet $\mathrm{AC}$ motors is investigated for safety critical applications. The motor modules are designed to provide both magnetic and electrical isolation between the phases, and the use of two modules also offers redundancy. This paper addresses an important issue, torque ripple and torque compensation due to the loss of a phase or phases in a practical dual motor drive. The mathematical models for reference current calculation in both healthy and various faulty operation modes are established under the zero torque ripple factor and minimum copper loss constraint conditions. These models are suitable for both sinusoidal and trapezoidal fault tolerant motor drives. The experimental results under various fault conditions are provided to verify the proposed fault remedial strategy.
\end{abstract}

\section{INTRODUCTION}

A number of studies have been reported in the literature investigating fault-tolerant motor drives, which primarily target safety critical applications. Brushless permanent magnet (PM) motor drives can have fault tolerant capability by minimizing the electrical, magnetic and thermal interaction between phases in the motor design and driving each phase by a separate $\mathrm{H}$-bridge inverter circuit [1]. The electrical fault detection methods and several fault remedial strategies for the brushless PM motor drive were studied in the literature [2-5]

However, the previous studies on fault tolerant motor drives were mainly concentrated on single isolated-phase fault tolerant PM motor drives. They do not address other potential faults, such as a complete motor drive failure due to power supply or controller failure. To reduce the risk of a complete motor failure and to provide redundancy, a dual fault-tolerant PM motor drive system was proposed in [6].

Torque ripple of motor drives is a critical concern in many applications where low acoustic noise, or friendly human-machine interactions are important [7]. For example, in the steer-by-wire applications, the capability of fault tolerance is not only required, in order to meet user's expectations, but also high levels of torque smoothness are demanded [8]. Some torque ripple minimization techniques in standard three phase PM motor drives were discussed in $[9,10]$. In addition, the torque pulsation reducing technique for multi-phase IPM motor drives were presented in [11]. These techniques are mainly classified into two categories. The first category includes techniques for proper motor design which makes the motor close to its ideal characteristics and therefore produces smoother torque. The second category includes the techniques for modifying the excitation currents and therefore minimizing torque pulsations.

An optimal torque control technique in a single fault tolerant PM motor drive with isolated phases was proposed in [12]. The optimal torque control strategy demonstrated by computer simulation enables ripple-free torque operation to be achieved while minimizing the copper loss under voltage and current constraints.

This paper addresses an important issue, torque ripple, in a dual fault tolerant PM motor drive and proposes a minimum torque ripple fault remedial strategy for various faults. The two three-phase 48 pole brushless permanent magnet AC (PM AC) motors are connected on a common shaft. The motor modules use concentrated windings, which minimize the magnetic coupling and also provide electrical isolation. In addition, each phase of the motor modules is driven by a separate single-phase H-bridge inverter. The proposed fault remedial strategy for torque ripple reduction is demonstrated using a real time motor drive system.

\section{PRINCIPLES OF MiNimUM TORQUe RiPPle CURRENT CONTROL}

\section{A. Potential Faults}

The most common faults in motor drives are winding and switch open-circuit and short-circuit faults. The fault analysis has shown that the rms short-circuit current and the average drag torque values under a switch short-circuit fault condition are bigger than the values under the winding short-circuit fault condition [13]. Therefore, when a switch short-circuit fault is detected and identified, this fault is transferred into a winding short-circuit fault by turning on the switch in the other leg of the same inverter circuit. In addition, after a switch open-circuit fault occurs, all the switches in this inverter circuit are turned off. Under the above assumption, the potential faults in a dual fault tolerant motor drive can be classified into onephase open-circuit fault, one-phase short-circuit fault, twophase open-circuit fault, two-phase short-circuit fault, three-phase open-circuit fault (including one motor module complete open-circuit fault due to power supply failure or controller failure) and three-phase short-circuit fault. 
These potential faults have to be detected prior to any fault remedial strategy being adopted. The fault detection methods have been studied previously in [14]. This paper aims to develop and implement current control methodologies to minimize the torque ripple under onephase open-circuit and short-circuit faults, two-phase open-circuit fault and one motor complete open-circuit fault in a fault tolerant motor drive with redundancy.

\section{B. Reference Current Model in Healthy Operation}

In general, whether the motor drive has a single motor module or two motor modules, the back-EMF voltages of an $n$-phase fault tolerant PM motor drive can be given as

$$
e_{j}=k_{e} \omega_{m} e_{j}\left(\theta_{e}\right)
$$

Here the subscript $j$ is an integer representing the phase number of the motor $(j=1,2, \ldots, n), k_{e}$ is the back-EMF constant, $\omega_{m}$ is the angular speed of the rotor and $\theta_{e}$ is the electrical rotor position. $e_{j}\left(\theta_{e}\right)$ is the unit back-EMF voltage of phase $j$ which is a function of the rotor position with a maximum amplitude of \pm 1 .

Considering a simple motor drive with two isolatedphases, the output torque $T_{0}$ can be calculated by:

$$
T_{0}=k_{e}\left[e_{1}\left(\theta_{e}\right) i_{1}+e_{2}\left(\theta_{e}\right) i_{2}\right]
$$

here $i_{1}$ and $i_{2}$ denote phase currents of the motor module.

It can be demonstrated that at any point in time, the minimum copper loss to produce a given output torque is obtained by keeping the ratio of the instantaneous phase currents equal to the ratio of the instantaneous phase backEMF voltages. This results in the following equations:

$$
\begin{aligned}
& i_{1}=\frac{e_{1}\left(\theta_{e}\right)}{e_{1}^{2}\left(\theta_{e}\right)+e_{2}^{2}\left(\theta_{e}\right)} \cdot \frac{T_{0}}{k_{e}} \\
& i_{2}=\frac{e_{2}\left(\theta_{e}\right)}{e_{1}^{2}\left(\theta_{e}\right)+e_{2}^{2}\left(\theta_{e}\right)} \cdot \frac{T_{0}}{k_{e}}
\end{aligned}
$$

Equations (3) and (4) are valid for back-EMF waveforms of any shape and can be extended to multiplephase single or dual motor modules with $n$ phases as follows:

$$
i_{j}=\frac{e_{j}\left(\theta_{e}\right)}{e_{1}^{2}\left(\theta_{e}\right)+e_{2}^{2}\left(\theta_{e}\right)+\ldots+e_{n}^{2}\left(\theta_{e}\right)} \cdot \frac{T_{0}}{k_{e}}
$$

\section{Reference Current Models in Faulty Operations}

The fault analysis study has shown that after the faults occur in the motor drive; the total output torque will be reduced. At the same time, the peak-to-peak torque ripple will be increased. In addition, the fault effect on output torque and torque ripple is worse under the phase shortcircuit fault condition due to the drag torque compared to the result obtained under the phase open-circuit fault condition. Therefore, it is necessary to adopt suitable fault remedial strategies to compensate the torque loss and reduce the torque ripple values.

Since the output torque is proportional to the phase current, the only way to maintain rated (or near rated) torque under faulted operation in a fault tolerant motor drive is to increase the current in the healthy phases.
If a phase has an open-circuit fault in a single or dual fault tolerant motor drive with $n$ phases, in order to obtain rated output torque and zero torque ripples and minimum copper loss, the currents in the healthy phases can be derived and expressed as:

$$
i_{j}=\frac{e_{j}\left(\theta_{e}\right)}{\sum_{j=1}^{n} e_{j}^{2}\left(\theta_{e}\right)-e_{k}^{2}\left(\theta_{e}\right)} \cdot \frac{T_{0}}{k_{e}} \quad j \neq k
$$

Here $k$ is an integer representing the faulty phase of the motor, which should be excluded in the above equation. For example, in a dual three phase motor drive where phase 4 suffers an open-circuit fault, $n$ and $k$ are equal to 6 and 4 . If phase $k$ has a short circuit fault, however, the current control of the healthy phases should satisfy the equation below.

$$
i_{j}=\frac{e_{j}\left(\theta_{e}\right)}{\sum_{j=1}^{n} e_{j}^{2}\left(\theta_{e}\right)-e_{k}^{2}\left(\theta_{e}\right)} \cdot\left[\frac{T_{0}}{k_{e}}+e_{k}\left(\theta_{e}\right) i_{k}\right] j \neq k
$$

Where $i_{k}$ is the short-circuit current in phase $k$, and the extra term $e_{k}\left(\theta_{e}\right) i_{k}$ represents the drag torque produced by the short-circuit current. It is obvious that in the case of a winding short circuit fault, due to the drag torque produced by the short-circuit current, the current in healthy phases will be significantly higher than the current in open-circuit fault operation in order to output the same torque as in healthy operation.

In addition, (6) can be extended to more than one phase open-circuit fault condition. If phase $k$ and $l$ are opencircuit fault, (6) becomes

$$
i_{j}=\frac{e_{j}\left(\theta_{e}\right)}{\sum_{j=1}^{n} e_{j}^{2}\left(\theta_{e}\right)-e_{k}^{2}\left(\theta_{e}\right)-e_{l}^{2}\left(\theta_{e}\right)} \cdot \frac{T_{0}}{k_{e}} \quad j \neq k, l
$$

\section{EXPERIMENTAL SETUP AND MOTOR CONTROL}

\section{A. Motor Setup and Controller}

Fig. 1 illustrates the block diagram of the dual fault tolerant PMAC motor drive that includes two identical three-phase fault-tolerant brushless PM motor modules with surface-mounted PM rotors, six H-bridge inverters with fault detection circuits, six Hall-effect current sensors, one encoder and two Microchip dsPIC30F4011 based motor controllers. In addition, the two motor modules are powered by separate power supplies. Fig. 2 is the picture of this experimental setup. The load consists of two permanent magnet $\mathrm{AC}$ generators and the output terminals of one generator are connected to a three phase rectifier and a rheostat which is used to adjust the output load value.

Table I describes the parameters of the motor module. In this motor setup, each motor module has three phases in which the back-EMF waveforms are sinusoidal with $120^{\circ}$ phase difference with each other. For the sake of simplicity, using phase 1, 2, 3 and phase 4, 5, 6 describe the phase numbers of the two motor modules. It should be noted that the back-EMF voltages of the two motor modules are aligned in this study. 


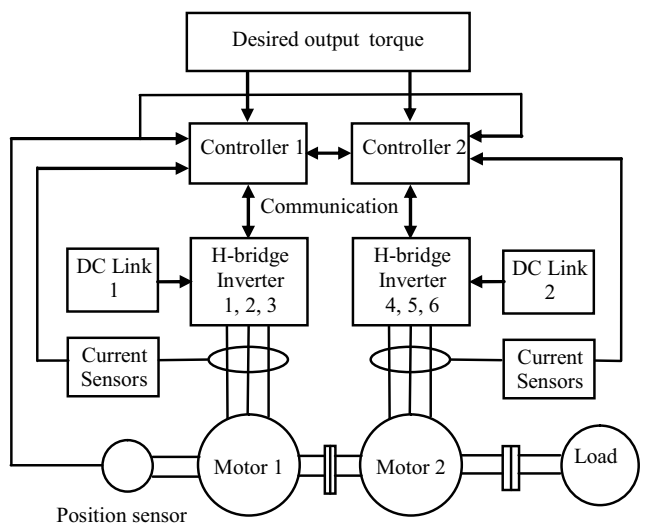

Figure 1. Block diagram of the dual fault tolerant motor drive

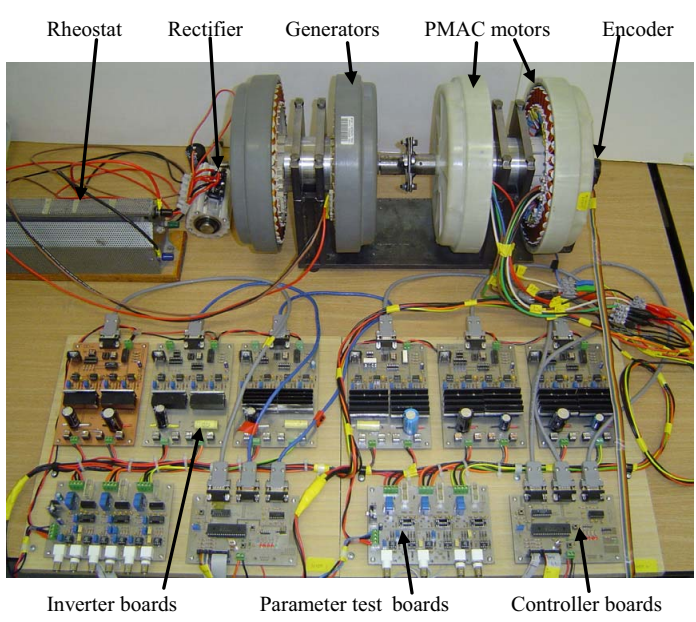

Figure 2. Picture of the experimental setup

TABLE I. MOTOR PARAMETERS

\begin{tabular}{|l|c|}
\hline \multicolumn{1}{|c|}{ Items } & Values \\
\hline Winding resistance $(\Omega)$ & 0.55 \\
\hline Winding inductance $(\mathrm{mH})$ & 2.1 \\
\hline Back-EMF constant $(\mathrm{V} / \mathrm{rad} / \mathrm{s})$ & 0.89 \\
\hline Number of pole pairs & 24 \\
\hline
\end{tabular}

\section{B. Current Control}

A hysteresis current control scheme is used to control the motor modules. In healthy operation, according to (5), the reference currents can be expressed by

$$
i_{j}(t)=I_{m} \sin \left(N_{p} \omega_{m} t-\phi_{j}\right) \quad j=1 \sim 6
$$

Here $I_{m}$ is the peak value of the current under healthy operation, which can be obtained from the desired output torque $T_{0}\left(I_{m}=T_{0} / 3 k_{e}\right), N_{p}$ is the number of pole pairs of the motor, and $\phi_{j}$ is the phase difference between phase $j$ and phase 1 .

If an open-circuit or short-circuit fault occurs in phase 4 , based on the assumption of sinusoidal back-EMF voltages and that the motor modules could be over-rated for a short period of time, (6) and (7) can be used to calculate the reference currents in the healthy phases to obtain the desired output torque as in healthy operation with minimum torque ripple and copper loss. The reference currents under the above conditions can be given as

$$
\begin{aligned}
& i_{j}(t)=\frac{\sin \left(N_{p} \omega_{m} t-\phi_{j}\right)}{1-\sin ^{2}\left(N_{p} \omega_{m} t\right) / 3} I_{m} \quad(j=1,2,3,5,6) \\
& i_{j}(t)=\frac{\sin \left(N_{p} \omega_{m} t-\phi_{j}\right)}{1-\sin ^{2}\left(N_{p} \omega_{m} t\right) / 3}\left[I_{m}+\frac{1}{3} \sin \left(N_{p} \omega_{m} t\right) i_{4}(t)\right] \\
& (j=1,2,3,5,6)
\end{aligned}
$$

Where $i_{4}(t)$ is the short circuit current in phase 4 and can be given by

$$
\begin{aligned}
& i_{4}(t)=\frac{k_{e} \omega_{m}}{\sqrt{R^{2}+\left(N_{p} \omega_{m} L\right)^{2}}} \sin \left(N_{p} \omega_{m} t-\phi\right) \\
& \phi=\tan ^{-1}\left(N_{p} \omega_{m} L / R\right)
\end{aligned}
$$

Here $R$ and $L$ are the resistance and inductance of the motor windings and $\phi$ denotes the phase difference between the short-circuit current and back-EMF voltage of phase 4. Obviously, the short-circuit current and phase difference are functions of rotor speed and the measured and calculated results are illustrated in Fig. 3.

In the real time motor control system, in order to increase the closed-loop control frequency, the above equations were implemented using look-up tables.

If motor module 2 suffers a complete open-circuit fault due to a power supply failure or motor controller failure, in order to obtain the same output torque as in healthy operation, the reference currents in motor module 1 can be given as

$$
i_{j}(t)=2 I_{m} \sin \left(N_{p} \omega_{m} t-\phi_{j}\right) \quad j=1 \sim 3
$$

\section{EXPERIMENTAL DEMONSTRATION}

It should be noted here that when experiments are performed, the phase currents of the two motor modules and the load current and voltage are monitored by the LABVIEW based data acquisition card (PXI-4472) which can measure eight channel analog signals simultaneously. The measured current and voltage waveforms are then saved in the computer for off-line data processing.
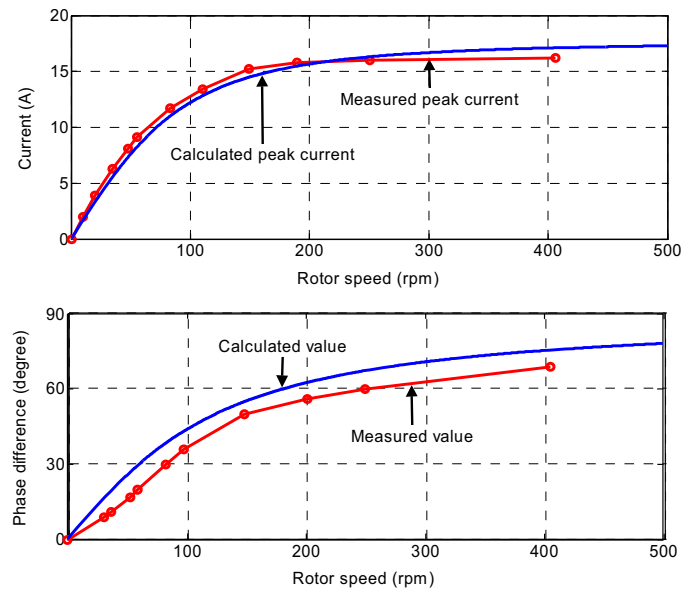

Figure 3. Peak short-circuit current (top) and phase difference (bottom) between the back-EMF voltage and short-circuit current of phase 4 at different rotor speeds 
Due to absence of a high-bandwidth in-line torque transducer, the electromagnetic torque waveforms in this paper are calculated using the measured phase currents and the known back-EMF voltage waveforms which are a function of the rotor position and motor angular speed. In addition, the torque ripple is calculated as the ratio of the peak-to-peak torque value and the mean value of torque.

\section{A. One-Phase Open-Circuit Fault Experiment}

A set of sample experimental results are given in Fig. 4, which shows the phase currents and the electromagnetic torque waveforms before and after an open-circuit fault is introduced in phase 4 at $1000 \mathrm{~ms}$ and no fault remedial strategy is adopted. From the analysis at these results we can conclude that the average output torque value under one-phase open-circuit fault condition was decreased to $7.68 \mathrm{Nm}$, which was about the $5 / 6$ of the torque under healthy operation $(9.01 \mathrm{Nm})$. Fig. 5 is given to demonstrate the effectiveness of the remedial strategy that is adopted to be able to minimize the torque ripple. As can be seen in these results, the peak-to-peak output torque ripple was reduced significantly when the remedial strategy is adopted (from $59 \%$ in Fig. 4 to $18 \%$ in Fig. 5), and the average output torque was maintained at the value under healthy operation.

The presence of torque ripple during healthy operation and after the adoption of the fault remedial strategy is due to the limitation of controller's word length, resolution of the encoder and current sensor, and the switching frequency. In addition, the hysteresis current control scheme can not eliminate the current error entirely and the real current causes torque ripples.

\section{B. One-Phase Short-Circuit Fault Experiment}

The two terminals of phase 4 winding were shorted to simulate a one-phase short-circuit fault. Fig. 6 is given to present the one-phase short-circuit fault operation in which no fault remedial strategy is employed. From the figure, it is can be seen that the electromagnetic torque waveform of motor module 2 is a periodic signal and is less than zero during a period of time. This implies that the short-circuit current in phase 4 generates negative torque during this period. As a result, the total average output torque is $5.38 \mathrm{Nm}$ which is much lower than the healthy torque value of $9.01 \mathrm{Nm}$. The peak-to-peak torque ripple reaches to $172 \%$ which is much higher than the healthy operation value of $19 \%$. In addition, the rotor speed is reduced to $32 \mathrm{rpm}$ from $87 \mathrm{rpm}$ in healthy operation.

Fig. 7 describes the experiment results of phase 4 shortcircuit fault operation in which the minimum torque ripple fault remedial strategy is applied. From the figure we can obtain that the total average output torque of the motor drive is $8.72 \mathrm{Nm}$ which is nearly equal to the healthy torque of $9.01 \mathrm{Nm}$ and the peak-to-peak torque ripple is $38 \%$ which is much lower than the value before the fault remedial strategy is adopted. It should be noticed that this fault remedial strategy only can be used for a short period of time due to the relatively large currents flowing in the healthy phases.

\section{Two-Phase Open-Circuit Fault Experiment}

Fig. 8 presents the experimental results in which the fault remedial strategy was adopted in the healthy phases after an open-circuit fault occurred in phase 4 and 5 at
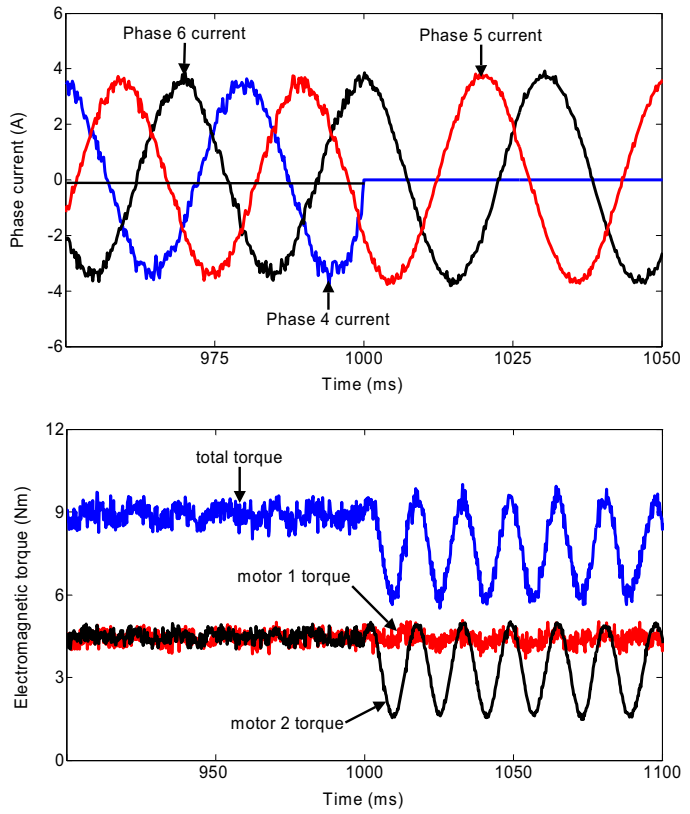

Figure 4. Measured phase current waveforms of motor module 2 (top) and the electromagnetic torque (bottom) waveforms before and after one-phase open-circuit fault occurred in phase 4 at $1000 \mathrm{~ms}$ and without any fault remedial strategy adopted
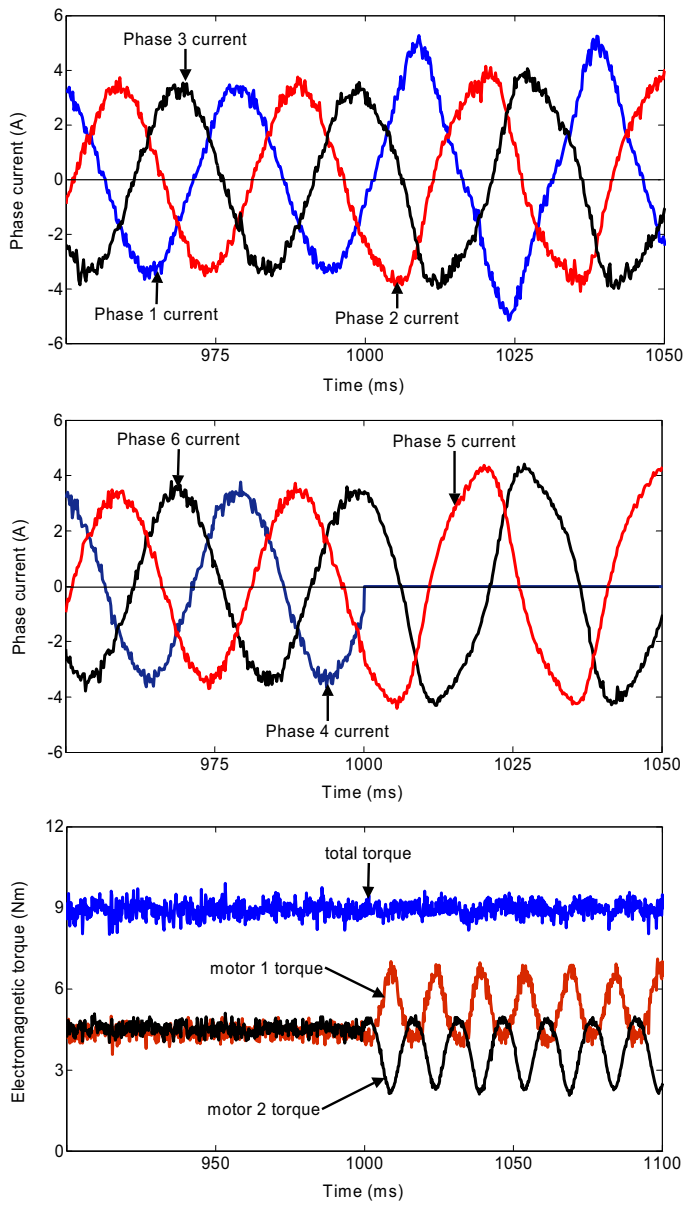

Figure 5. Measured phase current waveforms of motor module 1 (top), motor module 2 (middle) and the electromagnetic torque (bottom) waveforms before and after one-phase open-circuit fault occurred in phase 4 at $1000 \mathrm{~ms}$ and fault remedial strategy was adopted after fault 

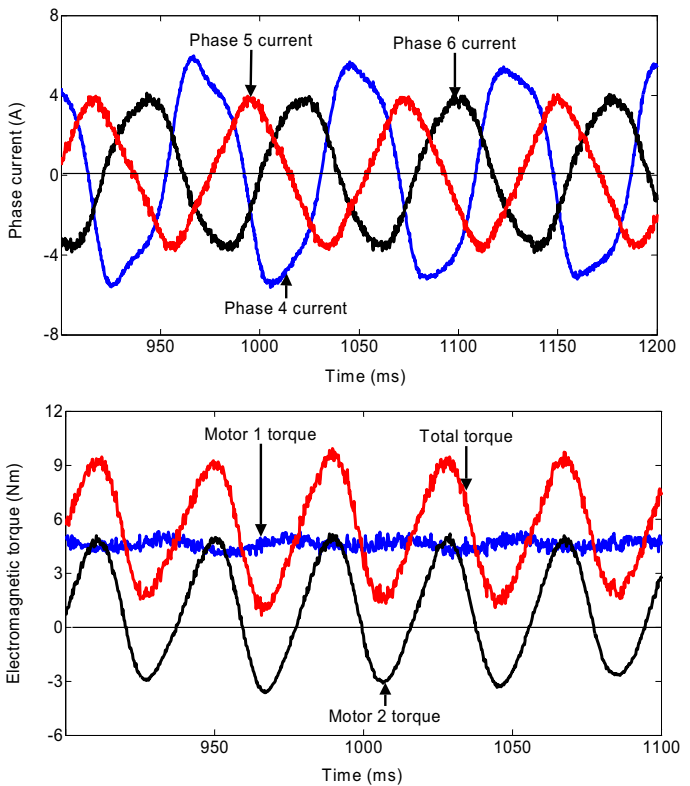

Figure 6. Measured phase current waveforms of motor module 2 (top) and the electromagnetic torque (bottom) waveforms when one-phase short-circuit fault occurred in phase 4 and no fault remedial strategy was adopted
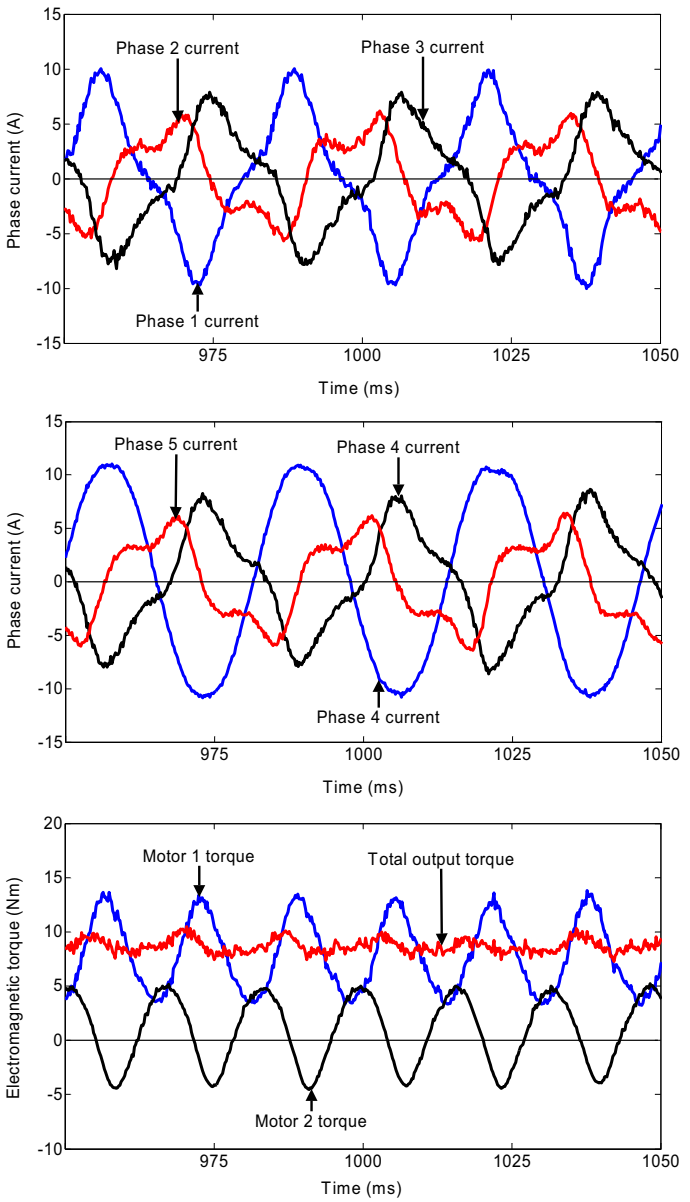

Figure 7. Measured phase current waveforms of motor module 1 (top), motor module 2 (middle) and the electromagnetic torque (bottom) waveforms when one-phase short-circuit fault occurred in phase 4 and fault remedial strategy was adopted
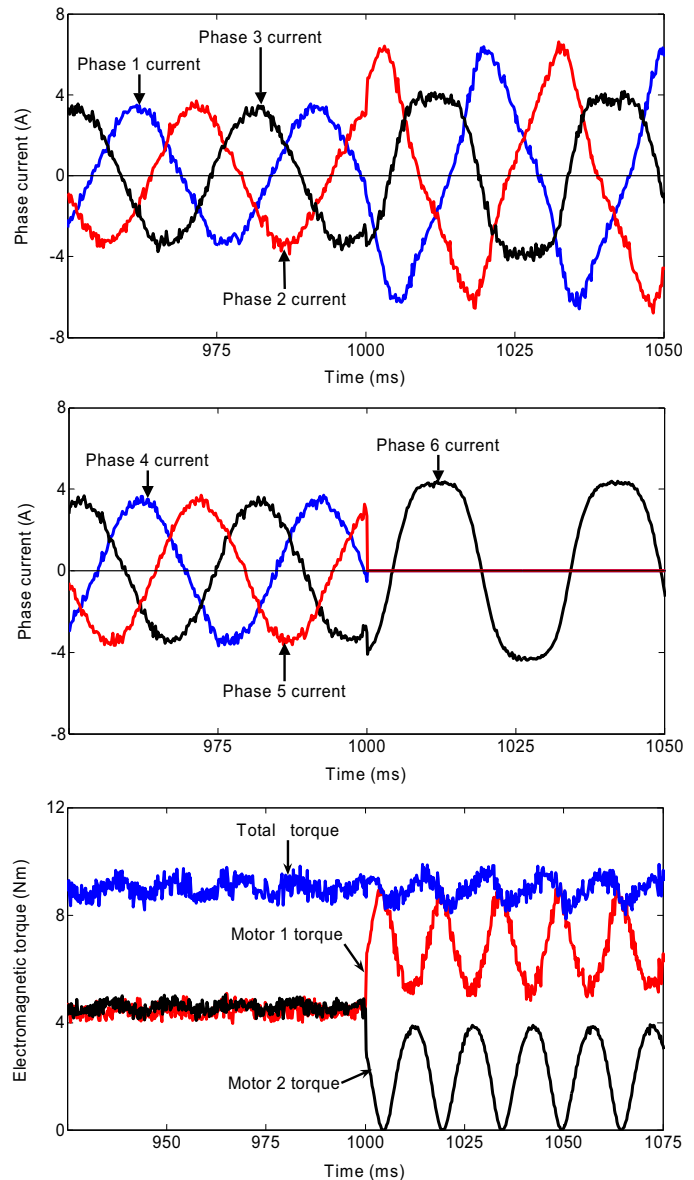

Figure 8. Measured phase current waveforms of motor module 1 (top), motor module 2 (middle) and the electromagnetic torque (bottom) waveforms when two-phase open-circuit faults occurred in phase 4 and 5 at $1000 \mathrm{~ms}$ and fault remedial strategy was adopted

$1000 \mathrm{~ms}$. It can be seen that the phase currents are not sinusoidal signals after the fault remedial strategy is adopted. In addition, from the experiment result, we can obtain that the average output torque is $9.12 \mathrm{Nm}$ and the torque ripple is $23 \%$ in two-phase open-circuit fault operation with the fault remedial strategy, and these values are almost the same as in healthy operation.

\section{One Motor Complete Fault Experiment}

Obviously, if motor module 2 has a complete opencircuit fault, the total output torque will be half the value of the healthy operation. Fig. 9 describes the experiment results of one motor complete open-circuit fault operation. Before $1000 \mathrm{~ms}$, the two motor modules were running in healthy operation. After motor module 2 had an opencircuit fault at $1000 \mathrm{~ms}$, the phase currents of motor module 1 were doubled. From the torque curves we can obtain that after the fault occurs the total output torque of the motor drive is $8.93 \mathrm{Nm}$ and the torque ripple is $21 \%$ which is almost the same value as in healthy operation.

The experimental results in different operating modes are summarized in Table II.

\section{CONCLUSIONS}

This paper emphasizes an important issue in many critical motor drive applications, which is maintaining low torque ripple in a fault tolerant PM AC motor drive with 
redundancy under fault conditions. The theoretical and practical background of the proposed motor drive is provided. The experimental results have proved that a correct fault remedial strategy can be implemented in a real motor controller to compensate the torque reduction due to a fault(s) and minimize the output torque ripple.

\section{REFERENCES}

[1] B. C. Mecrow, A. G. Jack, J. A. Haylock, and J. Coles, "Faulttolerant permanent magnet machine drives," IEEE ProceedingsElectric Power Applications, vol. Vol. 143(6), pp. 437-442, 1996.

[2] J. A. Haylock, B. C. Mecrow, A. G. Jack, and D. J. Atkinson, "Operation of a fault tolerant PM drive for an aerospace fuel pump application," IEEE Proceedings on Electric Power Applications, vol. Vol. 145(5), pp. 441-448, 1998.

[3] S. Green, D. J. Atkinson, B. C. Mecrow, A. G. Jack, and B. Green, "Fault tolerant, variable frequency, unity power factor converters for safety critical PM drives," Electric Power Applications, IEE Proceedings, vol. 150, pp. 663-672, 2003.

[4] S. Bolognani, M. Zordan, and M. Zigliotto, "Experimental faulttolerant control of a PMSM drive," Industrial Electronics, IEEE Transactions on, vol. 47, pp. 1134-1141, 2000.

[5] B. G. Park, T. S. Kim, J. S. Ryu, and D. S. Hyun, "Fault Tolerant Strategies for BLDC Motor Drives under Switch Faults," presented at 41st IEEE Industry Applications Conference, Florida, USA, 2006

[6] N. Ertugrul, W. Soong, G. Dostal, and D. Saxon, "Fault tolerant motor drive system with redundancy for critical applications," presented at 33rd IEEE Power Electronics Specialists Annual Conference, Cairns, Australia, 2002.

[7] M. Dai, A. Keyhani, and T. Sebastian, "Torque ripple analysis of a PM brushless DC motor using finite element method," Energy Conversion, IEEE Transaction on, vol. 19, pp. 40-45, 2004.

[8] A. Benedetti, N. Bianchi, S. Bolognani, M. D. Pre, P. G. Molari, P. Morelli, M. Tomasini, L. Tubiana, and M. Zigliotto, "PM motor drives for steer-by-wire applications," presented at Fourtieth IEEE Industry Applications Conference, Hong Kong, 2005.

[9] T. M. Jahns and W. L. Soong, "Pulsating torque minimization techniques for permanent magnet $\mathrm{AC}$ motor drives-a review," Industrial Electronics, IEEE Transactions on, vol. 43, pp. 321330, 1996.

[10] S.-H. Park, T.-S. Kim, S.-C. Ahn, and D.-S. Hyun, "A simple current control algorithm for torque ripple reduction of brushless DC motor using four-switch three-phase inverter," presented at IEEE 34th Annual Power Electronics Specialist Conference, 2003.

[11] L. Parsa and T. Kim, "Reducing Torque Pulsation of Multi-Phase Interior Permanent Magnet Machines," presented at 41st IEEE Industry Applications Conference, Florida, USA, 2006.

[12] J. Wang, K. Atallah, and D. Howe, "Optimal torque control of fault-tolerant permanent magnet brushless machines," Magnetics, IEEE Transactions on, vol. 39, pp. 2962-2964, 2003.

[13] J. Zhu, N. Ertugrul, and W. L. Soong, "Fault Analysis and Remedial Strategies on a Fault-Tolerant Motor Drive with Redundancy," presented at IEEE International Electric Machines \& Drives Conference, Antalya, Turkey, 2007.

[14] J. Zhu, N. Ertugrul, and W. L. Soong, "Detection and Remediation of Switch Faults on a Fault Tolerant Permanent Magnet Motor Drive with Redundancy," presented at 2007 Second IEEE Conference on Industrial Electronics and Applications, Harbin, China, 2007.
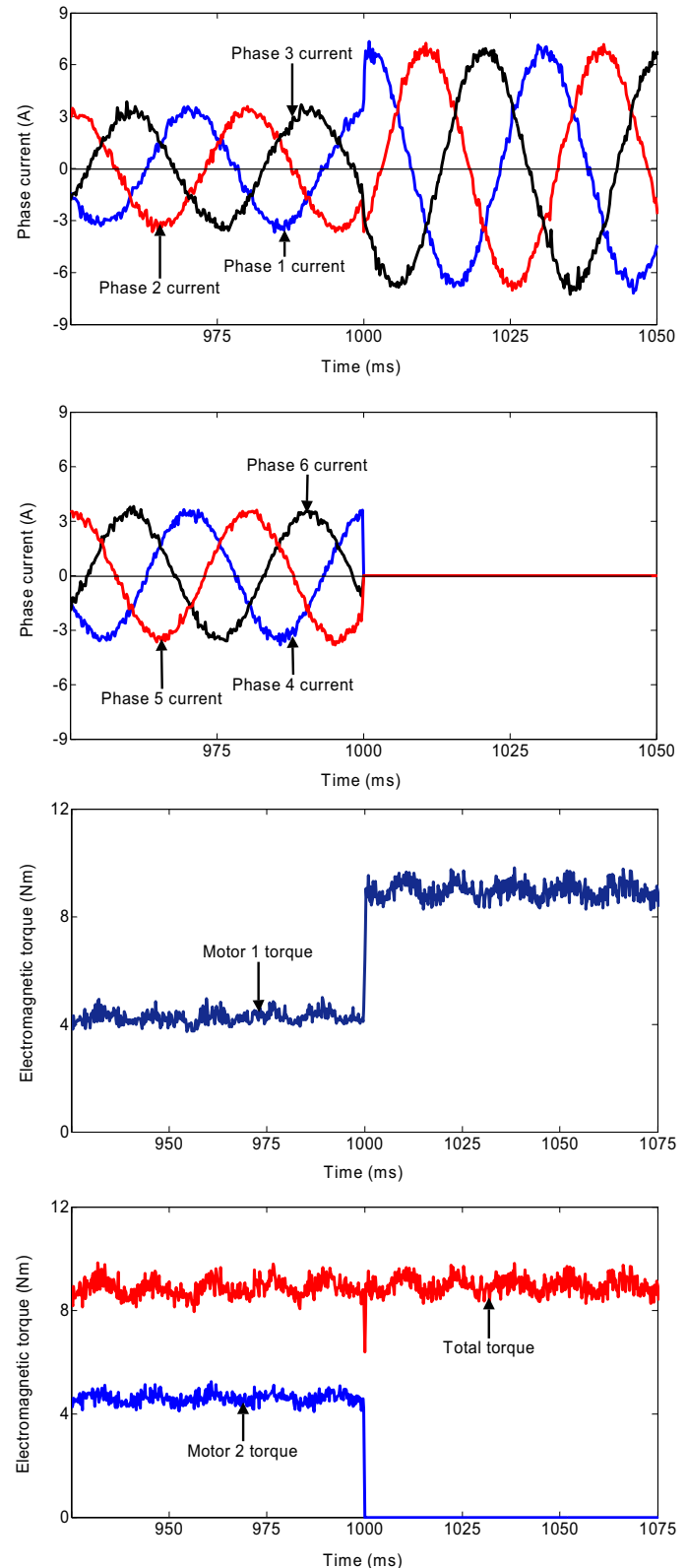

Figure 9. Measured phase current waveforms of motor module 1, motor module 2 and the electromagnetic torque waveforms (from top to bottom) when motor module 2 fails completely at $1000 \mathrm{~ms}$ and a fault remedial strategy was adopted

TABLE II. Summary of The EXPERIMENTAL Result in DifFerent Operating Modes

\begin{tabular}{|l|c|c|c|c|}
\hline \multirow{2}{*}{ Operating modes } & \multicolumn{2}{|c|}{ No fault remedial strategy } & \multicolumn{2}{c|}{ Optimal fault remedial strategy } \\
\cline { 2 - 5 } & Average torque (Nm) & Torque ripple (\%) & Average torque (Nm) & Torque ripple (\%) \\
\hline Healthy operation & 9.01 & 19 & - & - \\
\hline One-phase open-circuit fault & 7.68 & 59 & 8.09 & 18 \\
\hline One-phase short-circuit fault & 5.38 & 172 & 9.72 & 38 \\
\hline Two-phase open-circuit fault & 6.11 & 71 & 9.12 & 23 \\
\hline Three phase open-circuit fault & 4.57 & 22 & 8.93 & 21 \\
\hline
\end{tabular}

